Conference Proceedings Paper - Sensors and Applications

\title{
Carbon Tow Filaments and their Composites as Strain Sensors
}

\section{Catarina Lopes ${ }^{1, *}$, Luiza Rita Salvado ${ }^{1, *}$, Pedro Araújo ${ }^{1}$, Fernando Velez ${ }^{1}$, João Gomes ${ }^{1}$ Leszek Szojda ${ }^{2}$, and Marcin Gorski²}

${ }^{1}$ Unidade de Investigação Materiais Têxteis e Papeleiros, Universidade da Beira Interior, 6201-001 Covilhã, Portugal; E-Mails: kate_cial@sapo.pt (C.L.); paraujo@ubi.pt (P.A.); fjv@ubi.pt (F.V.); castro.gomes@ubi.pt (C.G.)

2 Silesian University of Technology, Address; E-Mails: Leszek.Szojda@polsl.pl (L.S.); Marcin.Gorski@polsl.pl (M.G.)

* Author to whom correspondence should be addressed; E-Mail: kate_cial@ sapo.pt (C.L.); lrbss@ubi.pt (L.S.); Tel.: +351-275-319-852; Fax: +351-275-319-723.

Published: 1 June 2014

\begin{abstract}
The use of carbon filaments polymer matrix composites for strengthening of buildings might allow self-sensing of the structural health monitoring of the building structure, sensing low strains by measuring the electrical resistance of the composite. This paper analyses the change of the electrical resistivity of carbon filaments embedded in epoxy during tensile tests, concluding that their electrical resistance increases with the strain. Therefore, normal carbon tows used for strengthening the structures, as the tested ones, may behave as sensor to detect small deformations (below 1\%) of the structure. Both volume electrical resistivity and contact electrical resistivity of the composite materials were analyzed, by introducing some specific and simple designs on the geometry of the filaments integrating the composite. The results may drive the development of strengthening textile fabrics with the ability of self-sensing low strains.
\end{abstract}

Keywords: Health Monitoring Structures; Carbon Filaments Polymer-Matrix Composites; Strain Sensors; Electrical Resistance.

\section{Introduction}

Carbon materials are becoming important structural materials in aircraft, transport, construction, communication and lighting [1]. High-performance properties and cost-effective characteristics of 
carbon fibres enhance these and other emergent applications. In construction, some traditional methods for strengthening of buildings are based on polymer matrix composites made of high performance fibers, such as carbon filaments. These strengthening systems, such as FRP (Fiber Reinforced Polymer) and TMR (Textile Masonry Reinforcement), might integrate sensors for the structural health monitoring of the integrity of the structure of the building. Several techniques have been proposed for this monitoring [2;3] is based on diverse type of sensors such as piezoelectric sensors and optical fibers. This paper focusses on the self-sensing capability of carbon filaments to sense strain and damage. Indeed, as carbon filaments and their polymer-matrix are electrically conductive materials, they may function themselves as sensor of strain by considering the relationships between their electrical and mechanical behavior $[1,4,5,6,7,8,9,10,11]$. The self-sensing technique is based on changes in electrical resistance caused by strain and also by disruptions of the conductive pathway within the structure of the sensing material [10-13,12]. The self-sensing technique has been mainly studied for carbon fibre reinforced polymer-matrix (CFRP) strips. However, this paper focusses on carbon fabrics and their ability for strengthening and self-sensing functions. Indeed, textile weaving technology allows an easy control of the conductive pathways within the fabric by controlling the positioning of the sensing filaments. Therefore, textile technology might produce efficient and cheap monitoring systems. So, it is important to test the electromechanical behavior of carbon filaments polymer-matrix composites. Moreover, this paper presents a study of the electrical resistance under low strain. In fact, in structural monitoring low strain represents damage in the structure that is not visually observed and is therefore a structural health parameter that is important to monitor. The strain monitoring by electrical resistance has been based in two types of measurement: the through-thickness conductivity and the longitudinal conductivity (along the filament direction) measurement [5, 12-13]. The former gives information on the number of contacts between filaments in the plane of the material and the last one gives information on the strain and fracture of the filaments. Therefore they have been also named contact electrical resistance and volume electrical resistance, respectively. In general, one observes an increase in the electrical resistance with an increase in strain [1, 6, 12-13], that is mainly due to the decreasing number of contacts between filaments during loading. This paper presents a study of the electrical and mechanical behavior of diverse carbon filaments epoxy composites, whose geometry and design of filaments were deliberately diversified to test and to enhance the ability of the filaments for self-sensing of low strains.

\section{Experimental Methods}

\subsection{Materials and specimens}

\subsubsection{Carbon tow}

Tow of PAN-based carbon filaments of enhanced modulus (SGL SIGRAFIL® C30 T050) was tested and also used to produce specific polymer-matrix composites. Table 1 presents its properties.

Table 1. Properties of the carbon continuous filament tow.

\begin{tabular}{|c|c|c|c|c|c|c|c|}
\hline Number & Fineness & Tensile & Tensile & Elongation & Filament & Density & Single \\
\hline filaments & $\begin{array}{l}\text { of tow } \\
{[\text { tex }]}\end{array}$ & $\begin{array}{l}\text { strength } \\
\text { [GPa] }\end{array}$ & $\begin{array}{l}\text { modulus } \\
\text { [GPa] }\end{array}$ & $\begin{array}{l}\text { at break } \\
{[\%]}\end{array}$ & $\begin{array}{l}\text { diameter } \\
{[\mu \mathrm{m}]}\end{array}$ & {$\left[g / \mathrm{m}^{3}\right]$} & $\begin{array}{l}\text { filament } \\
\text { resistivity } \\
{[u \Omega]}\end{array}$ \\
\hline
\end{tabular}




$\begin{array}{llllllll}50 \mathrm{k} & 3200 & 4.0 & 253 & 1.6 & 7 & 1.80 & 15\end{array}$

\subsubsection{Carbon filament epoxy-matrix composite probes to test at the dynamometer}

Diverse specimens of composite materials, made of the previous carbon filaments and of epoxy resin (S\&P Resin 55), were made. Both used materials, filaments and resin, are materials commonly used for reinforcement and strengthening of structures in building construction. The probes, to further test in the dynamometer, were produced through the following construction process:

- a first layer of epoxy-resin is spread on the top of an acrylic plate, which has a very smooth surface;

- then, carbon filaments are applied over this first layer of resin according to diverse and determined designs;

- further, another layer of resin is applied on the top of the filaments, embedding them very well;

- finally, the specimens are let to cure the resin for some days.

The use of acrylic plates, as supporting surface, makes easier to further remove the probes, before testing at the dynamometer. The design of the produced specimens is based on three hypotheses. First is, that low strain (up to $1 \%$ ) causes changes on the longitudinal electrical resistance. Second is, that some intentional cuts along the length of filaments, although random, cause disruptions on the conductive pathway that highlight the change of the longitudinal electrical resistance. Third is, that intentional designs based on crossing filaments enhance the contact electrical resistance.

Table 2 presents the summary of the general characteristics of the diverse specimens that were made and tested. The preliminary results obtained when testing the specimens with 3 days of cure were then used to drive and guide the design of the next specimens. Moreover, testing probes with different time of cure might help to understand what happens in the change of the electrical resistivity in function of the freedom of the filaments to move inside the composite.

Table 2. Specimens to test at the Dynamometer.

\section{Carbon filament tow in epoxy-resin with 3 days of cure}

Thin tow, with $<50 \mathrm{k} \quad$ Thin tow, with $<50 \mathrm{k}$ and with eight cuts

Thin tow over thin tow, $<50 \mathrm{k} /<50 \mathrm{k} \quad$ Thin tow, with $<50 \mathrm{k}$, long length (snake design)

Tow with 50k and with six cuts

Carbon filament tow in epoxy-resin with 7 days of cure

Tow over tow, $50 \mathrm{k} / 50 \mathrm{k} \quad$ Thin tow over tow, $<50 \mathrm{k} / 50 \mathrm{k}$

Thin tow, with $<50 \mathrm{k}$ and with 8 cuts $\quad$ Thin tow over thin tow, $<50 \mathrm{k} /<50 \mathrm{k}$ (snake over straight)

\subsection{Tensile-strain tests while recording the electrical resistance}

Tensile tests in the dynamometer (Adamel Lhomargy DY35) were performed and at the same time the electrical resistivity of the specimen was recorded with a multimeter (Keithley 197A). The probes were placed between jaws that were strong enough to hold the carbon filaments epoxy composites. The 
initial length was $500 \mathrm{~mm}$. The specimens were pulled at $1 \mathrm{~mm} / \mathrm{min}$ of velocity up to small displacements. The electrical resistivity was recorded connecting the multimeter to the extremities of the specimen, which were previously attached with a pressed spring, as shown in figure 1 .

Figure 1. (a) Example of probe in the dynamometer. (b) Emphasis on the connections to measure the electrical resistance.

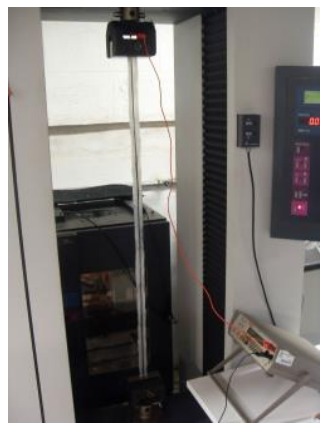

a)

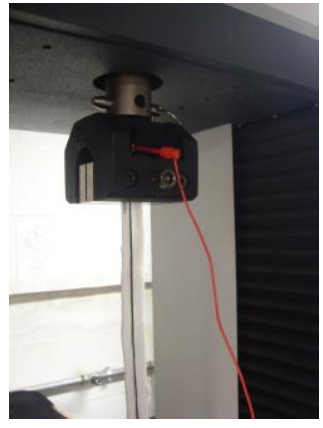

b)

\section{Results and Discussion}

Figure 2 presents the fractional increase in electrical resistance $\left(\Delta R / R_{0}\right)$, in percentage, as function of the strain.

Figure 2. The fractional electrical resistance versus strain of carbon filaments epoxy composite: (a) 3 days cure and (b) 7 days cure.

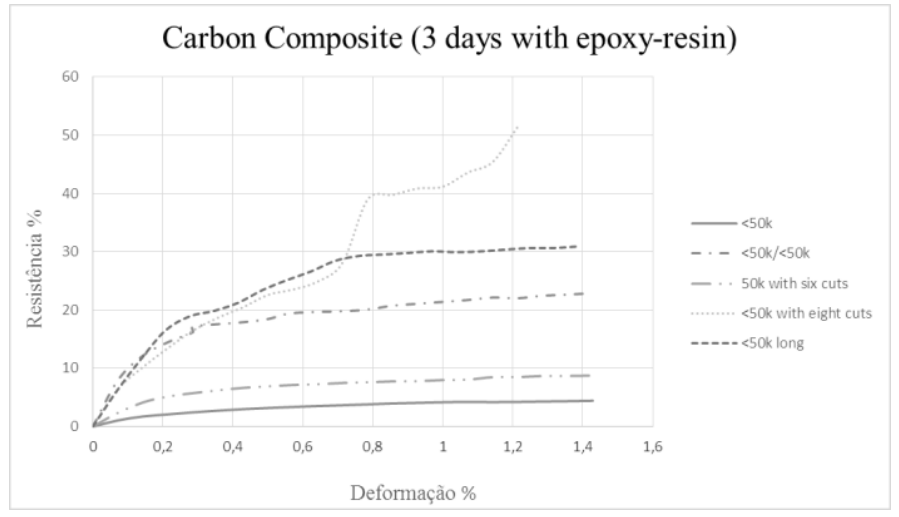

a)

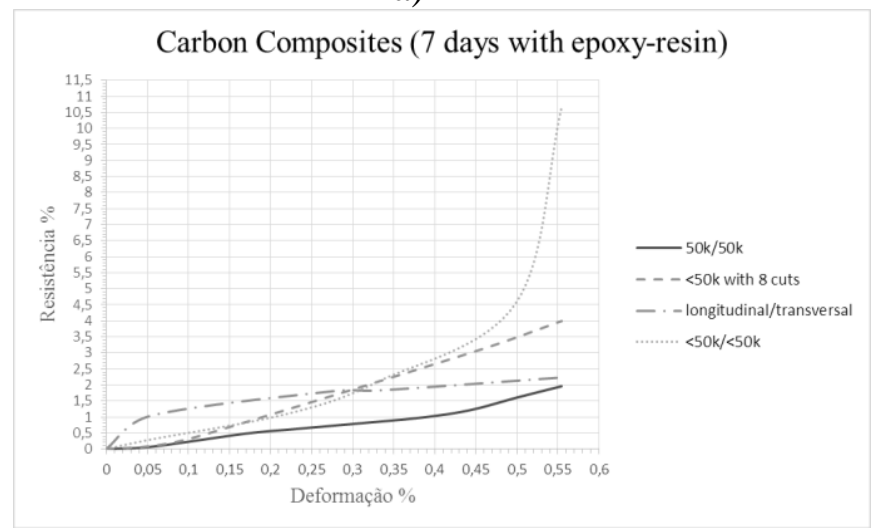

c) 
As observed in figure 2, for all tested specimens the small strains cause an increase in the electrical resistance. The initial resistance of these $500 \mathrm{~mm}$ long tows was deliberately diverse, varying from $9 \Omega$ (for the thick tow with eight cuts) to $350 \Omega$ (for the thin tow with long length - snake design). Despite this large range of magnitude of the electrical resistance, in all specimens the fractional change of the electrical resistance was sensing the deformation. But, as expected, higher electrical resistances enhance this sensing ability.

As reported by other authors $[6,10,12,13]$ the increase of electrical resistance caused by an increase in strain may occur because the filaments, that are covered with the epoxy-resin, become more aligned and thus the contact points between filaments decrease. This behavior is highlighted by the results obtained for the samples where the resin is not completely cured, presented in figure 2 a). In this case, the filaments have probably more freedom to move and become straight than when the resin is fully cured, enhancing this way the effect of the alignment of the filaments.

One should report that some other tested specimens presented a very unstable electrical resistance making difficult, even impossible, the recording of the results. For this raison they are presented in this paper. The formulated hypotheses are also confirmed as the introduction of deliberated disruptions on the conductive pathway, by random cuts, $(<50 \mathrm{k}$ with 8 cuts $)$ enhanced the sensing ability. Similarly, the sensing of strain by measuring the contact electrical resistance $(<50 \mathrm{k} />50 \mathrm{k})$ shows a very good performance.

\section{Conclusions/Outlook (COMPULSORY)}

For all tested specimens, the electrical resistance of the carbon filaments epoxy composites change with low strains, increasing with an increase of strain. One may conclude that the thick carbon tow of 50000 filaments normally used for strengthening the structures of buildings might behave as sensor to detect small deformations (below 1\%) on the concrete. Moreover, by introducing some specific and simple designs on the geometry of the filaments that integrate the strengthening textile fabric, the selfsensing ability of the fabric might be improved. Therefore, usual carbon strengthening materials may act as self-sensors for the health monitoring of buildings becoming a multi-function material that is light weight and low cost.

\section{Acknowledgments}

The authors acknowledge the European Union for financing the project 251373 (FP7-PEOPLE-2009IAPP) - INSYSM - Intelligent Systems for Structures Strengthening and Monitoring and the Brazilian Government for the PhD CAPES grant 9371/13-3.

\section{Author Contributions}

The author contribution is to improve the use of carbon differential material with multifunction at low cost and mantainance

\section{Conflicts of Interest}

The authors declare no conflict of interest. 


\section{References and Notes}

[1] D. D. L. Chung, "Carbon materials for structural self-sensing, electromagnetic shielding and thermal interfacing," Carbon N. Y., vol. 50, no. 9, pp. 3342-3353, Aug. 2012.

[2] S. W. J. Boller C, Structural Health Monitoring. DES Publishings, Inc, 2004.

[3] C. F-K, Structural Health Monitoring. DES Publishings, Inc, 2005.

[4] G. A. Balageas D, Fritzen C-P, Structural Health Monitoring. DES Publishings, Inc, 2006.

[5] D. D. L. Chung, "Structural health monitoring by electrical resistance measurement.pdf," Smart Mater. Struct., vol. 10, pp. 624-636, 2001.

[6] E. Sevkat, J. Li, B. Liaw, and F. Delale, "A statistical model of electrical resistance of carbon fiber reinforced composites under tensile loading," Compos. Sci. Technol., vol. 68, no. 10-11, pp. 2214-2219, Aug. 2008.

[7] L. Shen, J. Li, B. M. Liaw, F. Delale, and J. H. Chung, "Modeling and analysis of the electrical resistance measurement of carbon fiber polymer-matrix composites," Compos. Sci. Technol., vol. 67, no. 11-12, pp. 2513-2520, Sep. 2007.

[8] N. Angelidis, C. Y. Wei, and P. E. Irving, "Response to discussion of paper: The electrical resistance response of continuous carbon fibre composite laminates to mechanical strain," Compos. Part A Appl. Sci. Manuf., vol. 37, no. 9, pp. 1495-1499, Sep. 2006.

[9] Y. Nishi and M. Hirano, "Bending Stress Dependent Electrical Resistivity of Carbon Fiber in Polymer for Health Monitoring System,” Mater. Trans., vol. 48, no. 10, pp. 2735-2738, 2007.

[10] T. J. Swait, F. R. Jones, and S. a. Hayes, "A practical structural health monitoring system for carbon fibre reinforced composite based on electrical resistance," Compos. Sci. Technol., vol. 72, no. 13, pp. 1515-1523, Aug. 2012.

[11] H. Huang, C. Yang, and Z. Wu, "Electrical sensing properties of carbon fiber reinforced plastic strips for detecting low-level strains," Smart Mater. Struct., vol. 21, no. 3, p. 035013, Mar. 2012.

[12] D. D. L. C. Shoukai. Wang, "electrical behavior of carbon fiber polymer-matrix composites in the through-thickness direction.pdf," J. Mater. Sci., vol. 35, pp. 91-100, 2000.

[13] D. D. L. C. Xiaojun Wang, Xuli Fu, "Strain sensing using carbon fiber.pdf," Mater. Res., vol. 14, no. No 3, pp. 790-802, 1999.

(C) 2014 by the authors; licensee MDPI, Basel, Switzerland. This article is an open access article distributed under the terms and conditions of the Creative Commons Attribution license (http://creativecommons.org/licenses/by/3.0/). 